\title{
A ESCOLA NORMAL DO PARÁ: O NÚNCIO LEGALISTA PARA FORMAÇÃO DE PROFESSORES
}

\author{
Rogério Guimarães Malheiros \\ Rede municipal de Parauapebas \\ rogeriomalheiros@yahoo.com.br \\ Genylton Odilon Rêgo da Rocha \\ ICED-UFPA \\ genylton@gmail.com
}

\section{RESUMO}

Este artigo tem por tema o processo de criação e consolidação da Escola Normal do Pará. Nosso objeto de pesquisa, portanto, são os discursos dos Presidentes da Província do GrãoPará acerca da necessidade de se implantar, na capital da Província, cidade de Belém, uma Escola Normal destinada ao preparo específico de professores. Deste modo, nosso objetivo foi o de analisar os discursos dos Presidentes, de forma que pudéssemos depreender os objetivos destes para a implantação de uma Escola Normal, assim como as influências externas e internas, e, mais detidamente, a ambiência política e social em que fora constituído estes discursos em favor do "modelo" normalista de formação de professores. Como metodologia utilizamos a pesquisa documental a partir da análise do discurso, por meio da perspectiva de Mikhail Bakhtin, em especial o conceito de polifonia. Utilizamos como aporte teórico para a compreensão de nosso objeto a escola dos Annales, em especial, sua primeira e terceira gerações, relacionadas à compreensão das antíteses antigo/moderno, passado/presente e progresso/reação. Destarte, concluímos que a Escola Normal do Pará nasce de uma intricada questão de disputas políticas e ideológicas entre conservadores e liberais, e é possibilitada a partir de uma ambiência política e econômica.

Palavras-chave: Escola Normal do Pará; formação de professores

\section{SCHOOL OF NORMAL PARA: THE NUNCIO LEGALISTIC FOR TEACHER TRAINING}

\section{ABSTRACT}

This article has dealt with the process of creation and consolidation of Para Normal School. Our research object, so are the speeches of Presidents of Grand Pará Province about the need to deploy in the capital of the province, city of Bethlehem a Normal School intended for specific preparation of teachers. Thus, our objective was to analyze the speeches of Presidents, so that we could infer these objectives for the implementation of a Normal School, as well as external and internal influences, and more closely, the political and social environment in which these speeches made out in favor of "model" normalista teacher training. The methodology used to document research from discourse analysis, through the perspective of Mikhail Bakhtin, in particular the concept of polyphony. The theoretical contribution to the understanding of our object to the Annales school, in particular, its first and third generations, related to the understanding of ancient / modern antithesis, past / present and progress / reaction. Thus, we conclude that the Para Normal School is born of an intricate question of political and ideological disputes between conservatives and liberals, and is made possible from a political and economic ambience. Keywords: Para Normal School; Teacher training 
De acordo com as bases da lei, [...], o distincto administrador instituiu e organisou uma escóla normal, destinada á formar n'um curso de 3 annos, professores habeis a instruir e habilitar os actuaes, que ainda não estão preparados para bem desempenharem o magisterio; [...] (PARÁ, 1871, p. 9).

No Relatório do Presidente da Província do Grão-Pará, Abel Graça, datado de 15 de agosto de 1871, temos, claramente, os propósitos da oficialidade para a criação da Escola Normal do Pará, ou seja, essa instituição seria criada com o intuito de formar professores e habilitar os que já atuavam no sistema de instrução pública da Província. No entanto, em conformidade com este objetivo, está o projeto da classe abastada da Província e de seus dirigentes administrativos que pretendiam, para além do processo de habilitar os professores, formar agentes disseminadores dos ideais modernos de ordenamento, progresso e civilização.

Neste sentido, um mês após a publicação da Lei no 669, de 13 de abril de 1871, que cria a Escola Normal do Pará, ocorrera a instalação desta, e, em junho do mesmo ano, iniciaram-se as aulas, que, naquele momento, passariam a ser ministradas nas dependências do Liceu Paraense e do Colégio Nossa Senhora do Amparo. O que para o Presidente Abel Graça, significou grande progresso do sistema de instrução pública, haja vista que a Província não padeceria mais pela falta de preparo e vocação dos professores que há muito fora identificada, por seus antecessores, como sendo a grande causa de não se obter os avanços desejados para a instrução pública da Província, afirmando que "[...] com a criação da escóla normal [...] a provincia do Pará póde em pouco tempo ver emfim realisados os seus votos e o triunpho de seus esforços em pról da instrucção de seus filhos (PARÁ, 1871, p. 13).

Neste contexto, depreendemos que havia na Província do Pará, por ocasião da instalação da Escola Normal, um ambiente político, econômico e social propício para esta ação promovida pelo Governo da Província. Isto é, desde os anos finais da década de 1840, a alfândega de Belém vinha obtendo, ano após ano, elevadas arrecadações financeiras por suas exportações, fato que fora atribuído a crescente comercialização da borracha.

Somada a esta questão, está a introdução da navegação a vapor na Província, pois com este tipo de embarcação fora possível o transporte de grande quantidade de mercadorias para o porto de Belém, entre elas, a goma elástica, embarcações estas que além da quantidade, também efetuavam o transporte de mercadorias em curto espaço de tempo. ${ }^{\mathrm{i}}$

Deste modo, com o aumento da capacidade de transporte de mercadorias tivemos, por conseguinte, uma elevação da arrecadação alfandegária, possibilitando meios financeiros para por em prática o projeto de modernização da cidade de Belém e da Província. ${ }^{\text {ii }}$

Seguindo esta linha de raciocínio, podemos perceber que o melhoramento e expansão da instrução pública estiveram em consonância com o projeto de modernização pensado pela classe abastada da Província, que exigia, por ocasião de seu enriquecimento, devido ao comércio gomífero, grandes reformas urbanas e sociais, no sentido de alinhar a cidade de Belém aos costumes e hábitos civilizados, à luz do exemplo de organização urbana e social de Paris. ${ }^{\text {iii }}$

A ideia seria a de alinhar a Província do Pará ao que se entendia enquanto moderno e civilizado, todavia, seria necessário não apenas as reformas urbanísticas, mas também modelar os cidadãos paraenses aos hábitos considerados civilizados, missão esta 
conferida ao sistema de instrução pública da Província, o que está diretamente ligado a premente necessidade de se formar professores comprometidos com este modelo de instrução.

Autores como Villela (1992), Monarcha (1999) e Araújo (2008), por meio de suas obras, permitem-nos depreender que os ideais de progresso e civilização foram a tônica discursiva que justificava a necessidade de se instituir uma Escola Normal para se formar e habilitar professores. Estes autores ratificam ainda, que houve, tanto no caso da Província do Rio de Janeiro, quanto no caso de outras Províncias do Império, a exemplo de São Paulo, uma ambiência política, econômica e social que propiciaram a instalação da Escola Normal, o que pudemos também perceber no caso específico do Grão-Pará, por meio deste trabalho que ora apresentamos.

Cumpre destacarmos ainda que a obra "As Escola Normais no Brasil: do Império à República", organizada por Araújo, Freitas e Lopes (2008), apresenta-nos uma interessante coletânea de artigos, que acabam por ratificar o que constatamos na Província do GrãoPará, ou seja, apesar desta obra não abranger a Região Norte no processo de criação e consolidação das Escolas Normais no Brasil, a mesma apresenta-nos experiências da gênese e do percurso histórico desse tipo de instituição em diversas Províncias do Império, possibilitando-nos um olhar mais aguçado sobre as especificidades e permanências no caso paraense.

Nessas experiências apresentadas na mencionada obra, percebemos as nuanças do processo histórico-educacional de criação e consolidação das Escolas Normais ao longo do século XIX e início do XX, onde identificamos que nas distintas experiências, os anseios políticos e sociais por reformas urbanas, com ênfase aos preceitos modernos de ordem, civilização e progresso, permearam as concepções políticas e sociais em favor da implementação de medidas relacionadas a melhoria dos respectivos sistemas de instrução pública, por meio da promoção de formação docente, onde a Escola Normal desponta como modelo de instituição para melhor atender esses anseios.

Torna-se interessante destacarmos também, que os distintos projetos de criação das Escolas Normais, presentes na obra organizada por Araújo, Freitas e Lopes (2008), acabam por demonstrar que esta instituição esteve também centrada na perspectiva social de criação de novos hábitos sociais de consumo, de mobilidade social e de, fundamentalmente, constituição de mecanismos que viabilizassem a proliferação entre os cidadãos de valores específicos das sociedades urbanas e industriais, o que estava em consonância com os preceitos de modernidade presentes na obra do historiador Jacques Le Goff (2003). ${ }^{\text {iv }}$

Por essa forma, a opção pelo modelo normalista, nas Províncias, fora em função da supremacia do modelo social europeu, em especial o parisiense, entre a elite dirigente do Império e das Províncias em destaque, pois a Europa, neste momento, apresentava-se aos dirigentes imperiais e provinciais brasileiros como o que havia de melhor em matéria de modernidade. Todavia, não queremos aqui afirmar que apenas o modelo europeu esteve presente no imaginário dos dirigentes brasileiros, mas que este acabou por se sobressair entre os demais, o que se justifica pela própria tradição oriunda do período colonial. ${ }^{v}$

Destarte, a Lei $\mathrm{n}^{\mathrm{o}} 669$ de 13 de abril de 1871, representou o núncio legalista que atenderia esta premente necessidade de formação de professores, haja vista que sua promulgação fora em função dos discursos proferidos por sucessivos Presidentes da Província que figuravam o modelo normalista como o essencial para atender as prementes necessidades de preparo dos professores do Grão-Pará, o que não nos parece estranho, pois este modelo de formação de professores, assim como o projeto de modernização de Belém, 
também fora oriundo da França, que se apresentava à grande parte dos administradores da Província, como sendo o que havia de melhor em termos de modernidade e civilização.

Cumpre ressaltarmos, que para além desta premissa de modernidade e de civilização do povo, o sistema de instrução da Província, assim como seus professores, teriam que estar habilitados a formar uma consciência industrial entre os cidadãos da Província, haja vista que, tanto o Presidente Couto de Magalhães quanto o Secretário Geral da Província, Ferreira Penna, identificavam que estes não possuíam, naquele momento, uma premente necessidade de promover a industrialização da Província, muito em função dos recursos naturais disponíveis para sua subsistência, o que os proporcionava uma relação social específica com a natureza, levando-os a relegar à segundo plano a criação de indústrias no interior da Província (Cf. PARÁ, 1864, p. 7).

Ainda acerca do Relatório de 1871, apresentado pelo Presidente Abel Graça, destacamos que o referido presidente considerava que

[...] nenhum paiz alcançará jamais uma prosperidade real sem tomar por guia o desenvolvimento da intelligencia. A instrucção publica, que eu tomo como synonimo de instrucção popular, é tão necessaria á um povo, como a luz que nos faz distinguir uns dos outros: é o pharol que illumina o espirito dos cidadãos e ensina-lhes á serem bons paes, bons amigos e bons patriotas.

Se a necessidade da instrucção é tão imperiosa, o primeiro dever dos que têm á seu cargo promover o bem geral é procurar satisfazel-a (Id., 1871, p. 13).

Depreendemos, neste sentido, um avizinhar-se aos ideais modernos de instrução por meio da epígrafe em destaque, haja vista que Abel Graça chama atenção para à necessidade de se propagar as luzes por meio da instrução do povo, sendo um dever dos Governos promovê-la e satisfazê-la de acordo com as necessidades demandadas pela sociedade.

O que podemos inferir que se trata da influência do pensamento francês, do final do século XVIII, em especial o pensamento do filósofo Marquês de Condorcet, que por meio de seus ensaios sur l'instruction publique e seu Rapport de 1792, já publicizava seus ideais de instrução pública pautada como dever do Estado e como mecanismo de ilustração dos cidadãos franceses à luz da razão, da moral e do cientificismo. ${ }^{\mathrm{vi}}$

Ao tratar das questões referentes à influência de ideias e modelos de instrução oriundos do velho continente e dos Estados Unidos da América, depreendemos que a partir de 1867, após abertura à navegação internacional do rio Amazonas, tivemos um aumento significativo de circulação de pessoas, ideias e modelos de instrução que passaram a influenciar os enunciados dos administradores e dirigentes da instrução pública do GrãoPará.

Influência esta que não depositamos apenas a abertura do rio Amazonas a navegação internacional, mas também ao fato de alguns Presidentes da Província terem subsidiado a formação de alguns professores no Continente europeu, mais precisamente, na França, e à antiga relação estabelecida com o velho continente oriunda ainda de tempos coloniais que já mencionamos acima. ${ }^{\text {vii }}$

Quanto à influência do modelo estadunidense, ${ }^{\text {viii }}$ percebemos que fora em função dos ideais republicanos que estavam bem evidentes no Império do Brasil já no início da segunda metade do século XIX, que fora se acentuando paulatinamente até o final do século, quando, em 15 de novembro de 1889, os políticos do Império aderem oficialmente 
o republicanismo no Brasil por meio da proclamação da República dos Estados Unidos do Brasil, e aclamada no Pará um dia posterior, pela comissão republicana composta pelos comandantes do Exército e da Armada e pelos civis do Club Republicano do Pará. ${ }^{i x}$

Cumpre evidenciarmos que a própria abertura à navegação internacional do rio Amazonas fora devido pressões internacionais, em especial dos Estados Unidos, que pressionaram o Governo brasileiro, desde a primeira metade do século, pela autorização às suas embarcações, de explorarem o interior da Amazônia, fato que só fora normatizado a partir de 1867, por meio do Decreto de n 3.920 , de 31 de julho.

No tocante a essas especificidades políticas, econômicas e culturais, observamos o afloramento discursivo em prol da instalação de uma Escola Normal destinada a formar e habilitar os professores do Grão-Pará. Formação esta que deveria estar intimamente ligada ao projeto, da classe abastada e dos dirigentes da Província, em alinhar a sociedade paraense aos hábitos culturais parisienses.

Assim, depreendemos que o projeto de remodelamento da cidade, bem como dos hábitos de seus cidadãos, foram possíveis devido a crescente arrecadação alfandegária da Província, aliada a diversos fatores que já elencamos anteriormente. No entanto, percebemos que este projeto de modernização da cidade e de seus habitantes acabou por acotovelar-se nas especificidades amazônicas, haja vista que no interior da Província, não havia naquele momento uma premente necessidade de industrialização, o que evidenciamos anteriormente por meio do Relatório de Couto de Magalhães e Ferreira Penna, apresentado no ano de 1864, que demonstrara a relação social que os habitantes da zona do Tocantins mantinham com a natureza.

Além desta relação social com a natureza, havia ainda o problema da extensão do território da Província e a dispersão populacional neste território, que acabavam por dificultar o acesso e, por conseguinte, a promoção dos mecanismos de instrução do cidadão, que muitas vezes habitavam porções bem afastadas de qualquer núcleo populacional, o que os levava a permanecerem fadados ao analfabetismo.

Deste modo, o projeto de formação de professores pelo modelo normalista também fora pautado como um dos mecanismos para proporcionar uma instrução pública que pudesse desenvolver uma mentalidade industrial, que estivesse intimamente ligada aos ideais modernos de ordem, civilização e progresso, e de disseminação do ensino primário no interior da Província, onde fosse o elemento propagador destes ideais e que fosse permeado das premissas modernas de instrução, isto é, de moral, razão e cientificidade (Cf. MALHEIROS, 2012).

Destarte, o projeto de modernização da cidade de Belém e o projeto de promoção e eficiência do sistema de instrução pública, coadunavam no objetivo de disseminação dos ideais modernos de civilização e progresso na Capital e no interior da Província.

Vale ressaltarmos que são projetos oriundos de um contexto sociopolítico ainda da primeira metade do século, o que podemos constatar por meio dos relatos dos viajantes que estiveram em Belém neste período e pelos Relatórios dos Presidentes da Província, que evidenciavam as mudanças urbanísticas e culturais da cidade, e da premente necessidade de melhorias para o sistema de instrução pública da Província nos anos de nossa pesquisa, o que denota a íntima relação entre a modernização que se queria e a instrução que a possibilitaria.

Por essa forma, na concepção dos dirigentes da Província, para que se obtivessem relevantes resultados no sistema de instrução pública seria necessária a institucionalização de uma Escola Normal que possuísse a finalidade específica de formar e capacitar os professores do Grão-Pará à luz dos pressupostos modernos de instrução. 
O sistema de instrução da Província fora considerado como o meio de moldar os cidadãos paraenses para o vir a ser da Província, isto é, formar cidadãos civilizados, que passariam a fazer parte de um contexto social de modernidade, progresso e civilização. Neste sentido, fora premente a necessidade de se formar os professores do Grão-Pará por meio do modelo normalista, concebido como um modelo que melhor poderia atender as necessidades do Pará, haja vista que já havia obtido grande êxito em outros países e em outras Províncias do Império.

Entre os presidentes que ratificaram esta necessidade de criação de uma Escola Normal destinada a formar e habilitar os professores do Grão-Pará tivemos Soares D'Andréa, que esteve a frente do Governo da Província no Período de 1836 a 1839; Bernardo de Souza Franco, nos períodos de 1839 a 1840 e 1841 a 1842; João Antonio de Miranda, de fevereiro a novembro de 1840; Fausto d'Aguiar, que permaneceu a frente da Província no período de setembro de 1850 a agosto de 1852; Francisco Brusque, de junho de 1861 a janeiro de 1864; Lacerda Chermont (Barão d'Arary), que dirigiu a Província por vários períodos, entre eles, de 28 de junho a 27 de outubro de 1866, de 9 de abril a 1 de junho de 1867 e de 6 de agosto a 29 de setembro de 1868; Joaquim Raimundo Lamare, que exerceu a função no período de junho de 1867 a agosto de 1868; Abel Graça, de abril a setembro de 1870 e de julho de 1871 a junho de 1872; e por último, o Presidente Joaquim Pires Machado Portella, em seu curto mandato, que durou de janeiro a abril de 1871, quando fora de fato e de direito criada e instalada a Escola Normal do Pará.

Neste contexto, podemos depreender que os discursos tecidos em favor da criação de uma Escola Normal na Província do Pará data ainda da primeira metade do século XIX e, já a partir de 1850, fora intensificado e passou a ser objeto de discussão nos Relatórios dos Presidentes elencados acima, que, em sua maioria, defendiam esta instituição como a que melhor atenderia as necessidades de formação e habilitação dos professores do sistema de instrução pública do Grão-Pará.

Porém, em contraponto aos enunciados proferidos em favor da criação da Escola Normal na capital da Província do Pará, tivemos no Relatório do Presidente Leitão da Cunha, apresentado à Assembleia Legislativa Provincial no ano de 1858, um discurso contrário a estas aspirações pelo modelo normalista de formação de professores, haja vista que este Presidente, baseado em suas leituras acerca do tema, não concebia que esta instituição fosse capaz de sanar os problemas que a Província vinha enfrentando em seu sistema de instrução pública.

Para Leitão da Cunha, estas Escolas Normais “[...] que tendo tido origem e florescido na Europa, degenerarão completamente quando, transportadas para nosso paiz, [...]" (PARÁ, 1858, pp. 12-13). Ou seja, para Leitão da Cunha, as experiências da Província do Rio de Janeiro, Bahia, Minas Gerais e São Paulo, teriam sido a prova de que o modelo de instituição da Escola Normal não poderia sanar os problemas que haviam no sistema de instrução pública do Pará, em especial o problema da falta de preparo e vocação dos professores.

Como podemos perceber a criação da Escola Normal do Pará não fora uma unanimidade discursiva entre os dirigentes do Grão-Pará, mas destacou-se nos discursos da maioria dos Presidentes da Província, entre os anos de 1838 a 1872, como sendo a instituição que poderia sanar os problemas do sistema de instrução pública do Grão-Pará, haja vista que, como bem pontuou o Presidente Abel Graça, em seu Relatório de 1871, a Escola Normal do Pará seria capaz de remover "[...] estas causas efficientes do atraso da instrucção [...] (GRAÇA, 1871, p. 8). 


\subsection{A Lei $n^{0} 669$, de 13 de abril de 1871 , e sua repercussão na imprensa paraense}

Após a publicação da Lei $n^{\circ} 669$ de 1871, pelo então Presidente da Província do Grão-Pará, Joaquim Pires Machado Portella, os periódicos de Belém "O Liberal do Pará" e "O Diário de Belém”, representantes dos Liberais e Conservadores, respectivamente, logo se manifestam com leituras divergentes da mencionada Lei que instituía naquele ano, 1871, a Escola Normal do Pará.

No tocante as questões relacionadas a criação da Escola Normal do Pará, ambos os periódicos degladiavam-se, uma vez que para os conservadores a formação de professores pelo modelo normalista traria bons resultados e melhorias para o sistema de instrução pública da Província; enquanto que para os liberais, a Escola Normal não passava de uma medida paliativa e que não poderia resolver os problema do atraso do ensino na Província, pois a falta de uma infra-estrutura nas mais variadas Vilas, Cidades e demais localidades da Província, deixaria os professores formados por essa instituição sem as necessárias condições para o desenvolvimento profícuo de suas atividades.

Neste contexto, um mês antes da publicação da Lei no 669, o Jornal "Diário de Belém" estampou em sua primeira página um artigo, onde procurou observar, segundo a concepção do articulista, a importância da formação do "mestre" para a disseminação de uma instrução pautada na moral e no desenvolvimento da "intelligencia infantil".

É uma verdade incontestável que os defeitos mais notáveis da instrucção primária são devidos á pouca capacidade que em geral tem o corpo doutrinante.

Quem faz o bom discípulo é o mestre, e desde que este não tem as habilitações necessárias para bem guiar a intelligencia infantil que começa a desenvolver-se, desde que não tenha moralidade e sentimentos religiosos para incutir no coração ainda verde o amor aos bons costumes e práticas de moral civil e religiosa a instrucção deixa de dar bons fructos, porque a verdadeira educação é aquella que prepara a inteligência e o coração para a prática do bem.

[...] preparar bons mestres é preparar bons discípulos porque estes recebem d'aquelles as primeiras práticas de estudo, os primeiros gosos da intelligencia, que se desenvolvem a proporção que o mestre faz conhecer as vantagens que delles se colhe.

[...] O primeiro mestre é, pois, um dos primeiros guias do homem no caminho de sua vida (DIÁRIO DE BELÉM, 15 de março de 1871, pp. 12 apud BRITO, 2005, p. 30).

Na visão do periódico Conservador de Belém há uma premente necessidade de desenvolver na Província mecanismos para a formação de professores que pudessem propagar o ensino primário baseado nos "bons costumes", na "moral civil e religiosa", bem como em conhecimentos pautados no desenvolvimento da "intelligencia" da criança, o que marcaria o tom discursivo do Presidente Jaquim Pires Machado Portella no ato da aprovação da Lei no 669, de 13 de abril de 1871.

Trata-se também de uma maneira de anunciar e justificar a necessidade da criação de uma instituição destinada ao preparo específico de professores na Província, uma vez que, conforme a epígrafe, o articulista do Jornal fora enfático em afirmar que "[...] 
preparar bons mestres é preparar bons discípulos porque estes recebem d'aquelles as primeiras práticas de estudo, os primeiros gosos da intelligencia, [...]” (Idem).

Brito (2005) destacou, em seu trabalho, que as verdadeiras intenções do governo da Província fora o de manter sua estrutura administrativa intocável, daí a necessidade de se voltar para o espaço escolar, por meio de proposições e medidas que pudessem expandir sua ideologia e controlar, principalmente, os professores, o que o leva a concluir que a formação pensada para os professores, à luz do modelo normalista, possuía a finalidade de transmitir um conhecimento que refletisse os ideais da ordem vigente.

Acreditamos que a reforma da instrucção primária é a mais grandiosa empresa da civilização moderna, [...] a reforma deve começar pela base, isto é, pelo mestre que sem educação moral, intellectual e religioso não pode ser bom.

Uma escola normal ou um curso em que os aspirantes ao magistério se eduquem pela cabeça e pelo coração, e onde aprendam um methodo de ensino compatível com a intelligencia dos meninos é uma necessidade de que não deve ser addiada por aquelles que trabalham em favor da instrucção primária (Idem).

Depreendemos, por essa forma, que o periódico conservador "Diário de Belém" se tornou o porta voz governamental, de forma que o mesmo justificava a necessidade de criação de uma Escola Normal para a formação de professores, bem como a reforma da instrução primária como mecanismos de desenvolvimento dos preceitos modernos de ordenamento, civilização e progresso, que acabavam por permear os enunciados e debates dos dirigentes e políticos nacionais e dos Presidentes do Grão-Pará.

Por conseguinte, a inserção do Grão-Pará no mundo reconhecidamente moderno e civilizado perpassaria pela reorganização do sistema de instrução pública da Província e pela implementação de medidas de formação de professores, onde a Escola Normal desponta como modelo para alguns setores da sociedade, que exigem uma melhor qualificação dos professores como forma de se obter um profícuo resultado do sistema de instrução pública da Província, de forma que estes seriam a base da constituição de uma sociedade pautada na ordem econômica e social vigente.

O articulista do "Diário de Belém", por meio do artigo que debatemos até agora, enfatizou também que,

[...] transmittir as novas gerações o espírito nacional, as ideas Moraes e religiosas, que constituem a vida tradicional do povo; propagar os conhecimentos úteis para as classes inferiores da sociedade [...] Formar homens e cidadões offerecendo na educação da infância uma base segura a prosperidade publica e ao progresso da civilisação (Idem).

Como podemos notar, o Jornal "Diário de Belém" fora enfático, um mês antes da aprovação da Lei ${ }^{\circ}$ 669, de 13 de abril de 1871, em defender a relevância de se formar professores para o desenvolvimento dos preceitos modernos de ordenamento, civilização e progresso. Nesta parte final do artigo, depreendemos também a defesa de uma educação pautada numa moral e na própria religiosidade do povo, já que o Estado nacional, constitucionalmente, era adepto do catolicismo romano, por meio do sistema do padroado, ${ }^{\mathrm{X}}$ havendo uma estreita relação da instrução pública com a Igreja Católica, haja vista que 
muitos Presidentes da Província consideravam os párocos os melhores mestres que haviam na Província.

Todavia, contrapondo-se ao "Diário de Belém", por conseguinte, aos políticos conservadores, o Jornal "O Liberal do Pará", diversas vezes contesta as ações provenientes do Governo da Província. Nesse sentido, em maio de 1871, portanto, quase um mês após a criação da Escola Normal do Pará, o periódico de tendência liberal, em tons provocativos, contesta a eficiência da aplicabilidade das mudanças, legalmente autorizadas na área do ensino, pelo então Presidente Joaquim Pires Machado Portella, onde evidenciaram que,

Até que finalmente, depois de oito dias de silêncio apresentou-se o Diário de Belém, defendendo-se do Novíssimo regulamento da instrucção pública.

[...] O Novíssimo regulamento de instrucção pública é obra de momento, cheio de imperfeições e acovas, capaz de prestar-se a todos os sophismos com que se poderá inutilizar suas melhores disposições, carregado de espantoso pessoal administrativo que só serviria para perpetuar a morosidade dos actos da administração, e para a perseguição dos professores desaffeiçoados.

Provocamos o Diário de Belém a que nos declare, sem rodeios, francamente, como acabamos de fazer, e em nome do partido a quem diz pertencer:

$1^{\circ} \mathrm{Si}$ quer a instrucção espalhada pelo povo com liberdade e sem peãs [prisões]

$2^{\circ} \mathrm{Si}$ aceita a fundação de escholas primarias noturnas, onde o povo vá beber a necessária instrucção, que os torne aptos á conhecer seus direitos civis e políticos.

[...] $4^{\circ}$ Si dese a criação da escola normal, onde se preparem professores que, cônscios de sua dignidade, se não curvem a importância menos decorosas.

Entretanto acompanhemos por agora a redação do Diário.

Diz ella que só uma opposição mesquinha seria capaz de negar ao sr. Portella a justa gratidão que lhe devemos.

Si o povo paraense deve gratidão ao Sr. Portella, que destruiu a obra monumental do sr. Siqueira, é natural que deva execração a este ultimo acto reprovado que praticou, acto que forçou seu correligionário a pôr o sello official da desmoralização (O LIBERAL DO PARÁ, O Regulamento da instrucção pública, 5 de maio de 1871 , p. 1 apud. BRITO, 2005, p. 32).

Como podemos perceber, as prerrogativas relacionadas ao novo regulamento da instrução pública e a criação da Escola Normal do Pará, provocaram um clima de tensão entre as classes políticas da Província. Segundo o periódico dos liberais, as ações e medidas relativas a instrução pública promovidas, nos últimos meses, pela presidência da Província, à época dirigida por Joaquim Pires Machado Portella, além de tentarem mascarar a morosidade e falta de eficiência do poder público neste ramo, acaba por tentar coagir os professores que não eram adeptos do conservadorismo governamental.

Conforme epígrafe acima, depreendemos que há forte disputa entre os jornais "Diário de Belém", de tendência conservadora, que defendia as medidas da Presidência da Província relacionadas ao sistema de instrução pública, e "O Liberal do Pará", de tendência liberal, que questionava a eficiência e as verdadeiras intenções do poder público para com 
as medidas de reorganização do sistema de instrução pública e a criação da Escola Normal do Pará.

O periódico dos liberais evidencia também a necessidade de se implantar o ensino noturno nas escolas da Província como forma de garantir ao povo o direito à instrução e a conhecer seus direitos civis e políticos, além do princípio de liberdade de ensino, o que nos leva a concatenarmos ao que fora defendido pelos franceses no final do século XVIII e ao que Ferreira Penna havia debatido em seu artigo publicado no jornal "Colombo" no ano de 1869. Vale ressaltarmos que Ferreira Penna também era adepto da tendência liberal, apesar de compor por vários anos o Governo da Província como Secretário Geral de Governo.

Em meio a essas controversas políticas e ideológicas é que fora criada a Escola Normal do Pará, onde os conservadores exaltavam tal medida, enquanto que os liberais a ponderavam e teciam pontuais críticas. No entanto, como explicita Brito (2005), em meio às vaidades pessoais dos Presidentes da Província, os mesmos acabavam por entrelaçar as questões político-partidárias e os projetos governamentais que porventura viessem a beneficiar o sistema de instrução do Grão-Pará. Como exemplo emblemático, temos no ano de 1872 a extinção da Escola Normal do Pará por meio da Lei ${ }^{\circ}$ 757, de 19 de dezembro do mesmo ano, sancionada pelo vice-presidente da Província, Barão de Santarém, onde determinou que,

\footnotetext{
Art. $1^{\circ}$. Fica extincta a escola normal, sendo o respectivo curso anexado ao Lycêu Paraense.

$[\ldots]$.

Art. $6^{\circ}$ As alumnas da referida escola, que já começaram o curso continuarão a ser leccionadas no collegio de N. S. do Amparo pelos professores do ensino respectivo, até que as mesmas o tenham concluído. $[\ldots]$.

Art. $7^{\circ}$. Fica em pleno vigor para os alumnos do Lycêu Paraense, que concluírem o curso normal, as mesmas vantagens e garantias concedidas pelo regulamento da escola.

[...].

Art. $11^{\circ}$ Revogam-se as disposições em contrário (PARÁ, Lei no 757, de 19 de dezembro de 1872).
}

Deste modo, a Escola Normal do Pará, com um pouco mais de um ano e meio de existência legal, é extinta e anexada ao Liceu Paraense. No entanto, a lei que extingue a Escola Normal resguarda o direito das alunas do curso normal do Colégio Nossa Senhora do Amparo em finalizá-lo, haja vista que, como havíamos pontuado anteriormente, os cursos da Escola Normal do Pará fora instalado, inicialmente, nas dependências do Liceu Paraense e do Colégio Nossa Senhora do Amparo (Cf. PARÁ, 1874).

Destarte, a Escola Normal do Pará esteve, desde sua criação, em meio as disputas políticas e ideológicas entre liberais e conservadores, disputas estas que no final da década de 1880 resultaria na mudança de regime governamental no Brasil, ou seja, na mudança do Império para a República. Porém, a partir de 1874 a Escola Normal do Pará volta a ser organizada pelo Governo da Província, ${ }^{x}$ estendendo suas atividades por longos anos durante o século $\mathrm{XX}$, formando professores, que em meio as disputas políticas e sociais, foram também alvos de duras críticas (Cf. BRITO, 2005).

Não nos deteremos nesse trabalho nas especificidades e nuanças da historicidade dos professores formados pela Escola Normal do Pará, nem mesmo no currículo e critérios 
adotados para o ingresso nessa instituição, haja vista que optamos por procurar observar o contexto social, político e econômico que levou o Governo da Província do Pará a instalar uma Escola Normal destinada ao preparo específico dos professores primários da Província, o que procuramos fazer privilegiando os discursos dos Presidentes da Província, no período de 1838 a 1871, de forma que pudéssemos, por meio da análise do discurso dos mesmos, observar os pressupostos políticos e ideológicas que marcaram a historicidade daqueles que estiveram a frente do Governo do Grão-Pará ao longo dos anos que delimitamos para nosso estudo.

Essas questões referentes ao currículo, critérios de ingresso e a própria repercussão social que os professores formados pela Escola Normal do Pará tiveram, poderá ser objeto de estudos em outros trabalhos, haja vista que é preciso dedicar grande atenção a essas questões que as reconhecemos de grande valia para a história social e para a história da educação do Pará, tratam-se de outras possibilidades investigativas desse rico processo que foi a criação e consolidação da Escola Normal do Pará.

Por fim, destacamos que a Escola Normal do Pará fora objeto de aspiração política e social que estiveram pautadas em um modelo de ensino e sociedade, modelo este que já evidenciamos em inúmeros momentos deste trabalho como sendo o parisiense. Desta maneira, não nos parece estranho a opção feita pelo modelo normalista de formação de professores, haja vista que este fora oriundo da França, na segunda metade do século XVIII, que inicialmente, por ocasião de sua gênese no século XVII, esteve sob a gerência da Igreja Católica e, posteriormente, fora instituído pelo Estado francês no período thermidor, devido proposição feita por Lakanal durante a Convenção Nacional francesa de 1794.

Após apreciação da proposição de Lakanal, a Convenção Nacional francesa adota para a França o modelo normalista de formação de professores, proporcionando, cinco anos após a eclosão da Revolução Francesa, a fundação de uma Escola Normal, que teve um curto prazo de existência, de janeiro a maio de 1795, mas que influenciaria diversos sistemas educacionais durante o século XIX, entre eles o do Grão-Pará, onde seus dirigentes o adotaram como modelo e, por ocasião do projeto de modernização da cidade de Belém, o adaptaram para atender este objetivo, isto é, modelar a cidade e seus cidadãos à luz das premissas modernas de ordem, civilização e progresso.

Procuramos, nesta parte final de nosso trabalho, delinear os pressupostos discursivos dos Presidentes da Província do Pará que, permeados do ideal social moderno, elegeram a instrução como elemento civilizador e propagador dos ideais de ordenamento e progresso, pautados na constituição de uma mentalidade industrial entre os cidadãos do Grão-Pará como forma de aplicabilidade do projeto da classe abastada da Província que pretendiam alinhar o Grão-Pará aos costumes e hábitos europeus. Por essa forma, reconheceram no modelo normalista de formação de professores o meio pelo qual poderiam doutrinar os agentes propagadores desses ideais no interior da Província, que estivessem afinados com suas políticas e ideais de modernização da Província.

No entanto, depreendemos que não fora uma tarefa fácil e tão pouco fora uma unanimidade entre a classe política da Província, pois houve grande resistência dos políticos liberais a este projeto do Governo em formar um "exército" de professores que comungassem de sua ideologia política. Além, do desejo de alguns políticos e intelectuais liberais em adotar o modelo estadunidense de ensino para o Grão-Pará e para o Império do Brasil.

Não poderíamos encerrar nossa narrativa, sem destacarmos uma importante questão, isto é, a falta de medidas e debates sobre a necessidade de formação para os 
negros da Província, que eram numericamente significativos na sociedade paraense da época, mas os dirigentes e deputados provinciais ignoraram essa presença em seus debates e ações relacionadas ao sistema de instrução pública, uma vez que em nenhum momento de seus Discursos, Relatórios, Ofícios e Falas direcionadas à Assembleia Legislativa Provincial, dedicaram atenção a essa questão.

\section{Quadro no 01}

Escravos: Divisão por Sexo e Faixa Etária no Município de Belém, 1850-1870

Fonte: 178 Inventários post-mortem - Arquivo Público do Estado do Pará.

Total de Escravos: 2.263

\begin{tabular}{|c|c|c|c|c|c|c|c|c|c|c|c|c|}
\hline \multirow[b]{3}{*}{ ANOS } & \multicolumn{6}{|c|}{ Faixa Etária $\left(\mathbf{n}^{0}\right)$} & \multicolumn{6}{|c|}{ Faixa Etária (\%) } \\
\hline & \multicolumn{2}{|c|}{ Até 12 anos } & \multicolumn{2}{|c|}{ 13-45 anos } & \multicolumn{2}{|c|}{ + de 45 anos } & \multicolumn{2}{|c|}{ Até 12 anos } & \multicolumn{2}{|c|}{ 13-45 anos } & \multicolumn{2}{|c|}{ + de 45 anos } \\
\hline & MAS & FEM & MAS & FEM & MAS & FEM & MAS & FEM & MAS & FEM & MAS & FEM \\
\hline $1850-1854$ & 56 & 71 & 86 & 91 & 29 & 17 & 16,00 & 20,28 & 24,57 & 26,00 & 8,29 & 4,86 \\
\hline 1855-1859 & 120 & 104 & 147 & 161 & 50 & 60 & 18,69 & 16,20 & 22,90 & 25,08 & 7,78 & 9,35 \\
\hline $1860-1864$ & 84 & 120 & 118 & 127 & 32 & 41 & 16,09 & 22,99 & 22,60 & 24,34 & 6,13 & 7,85 \\
\hline $1865-1870$ & 153 & 111 & 175 & 217 & 48 & 45 & 20,43 & 14,82 & 23,36 & 28,97 & 6,41 & 6,01 \\
\hline
\end{tabular}

No caso específico da capital da Província, cidade de Belém, conforme o quadro de $\mathrm{n}^{\mathrm{o}}$ 01, o número de negros escravizados, no período de 1850 a 1870, era de 2.263 , entre crianças, jovens e adultos que ficaram fadados ao analfabetismo das matrizes educacionais brasileiras, haja vista que, voltamos a afirmar, em nenhum momento dos Discursos, Falas, Relatórios e Ofícios da Presidência da Província houve alguma menção à necessidade de se instruir o negro liberto ou escravizado.

Fato este que nos leva a depreender que o projeto de instrução e de formação de professores do Grão-Pará esteve centrado na necessidade de civilizar e formar o cidadão, com claros objetivos de possibilitar a adesão deste cidadão ao projeto de sociedade da classe abastada da Província, que seguindo a lógica econômica internacional, necessitava de trabalhadores operosos e aptos a desenvolver as atividades industriais em voga na Província. Não havendo, por conseguinte, a necessidade premente de instruir o negro, pois havia também o receio de que por meio do processo de instrução, estes se organizassem e promovessem um levante contra o Estado e a ordem social estabelecida.

Por fim, comungamos com Xavier (1992) e França (1997), quando evidenciam que os reais objetivos do Império era a promoção de uma educação de elite para a elite, restando ao povo apenas uma instrução insipiente para se garantir e propagar os ideais de educação e sociedade que se queria para o Brasil, assim como para o Grão-Pará, o que acaba por contrastar com seus próprios discursos, que baseados nos pressupostos iluministas, primavam por uma instrução que promovesse a conscientização dos direitos e deveres do cidadão, onde estes pudessem estar aptos a corroborar com a sociedade por meio de proposições legais que viessem a melhorar a sociedade como um todo.

Trata-se do contraste do discurso e da prática, pois por meio do discurso os dirigentes e políticos do Império e os da Província do Grão-Pará tentavam mascarar seus reais objetivos, demonstrando que a própria constituição discursiva destes, estavam a serviço da empreitada conservadora da ordem social vigente.

Nesse contexto, procuramos demonstrar que o Grão-Pará não esteve alheio a essas questões, nem ao projeto nacional de criação e consolidação das Escolas Normais, pois logo após a criação da primeira Escola Normal do Brasil, na cidade de Niterói, Província 
do Rio de Janeiro, já se repercutiu na Província a necessidade de criação de uma instituição destinada ao preparo específico de professores à luz do modelo normalista já implementado na Província sede da corte imperial brasileira.

Fato este que demonstramos por meio da Lei $\mathrm{n}^{\circ} 33$ de 1839, durante o Governo do Presidente Bernardo de Souza Franco, que apesar de não ter sido concretizada, fora a primeira iniciativa legal do Governo da Província do Grão-Pará em instituir uma Escola Normal de formação de professores primários, o que só fora concretizada, após inúmeros discursos e aspirações dos dirigentes da Província, por meio da Lei $\mathrm{n}^{\circ} 669$, de 13 de abril de 1871, que criou a Escola Normal do Pará, logo instalada nas dependências do Colégio Nossa Senhora do Amparo e do Liceu Paraense.

\section{Considerações finais}

Cumpre destacarmos que o que nos motivou a pensar e elaborar essa narrativa fora um certo silenciamento da região Norte, por conseguinte, do Grão-Pará, nas questões relacionadas ao projeto de criação e consolidação das Escolas Normais no Brasil, o que nos causou uma inquietação.

Tivemos o intuito de desvelar as nuanças políticas e sociais que levou a criação da Escola Normal do Pará na década de 1870, do século XIX, bem como o de entendermos os discursos da oficialidade da Província quanto a necessidade de se formar e capacitar os professores à luz dos ideais de ordenamento, progresso e civilização.

Longe, portanto, de pretender ser uma análise exaustiva sobre o tema aqui proposto, este artigo foi concebida com a intenção de problematizar, de forma inicial, certas questões já cristalizadas na historiografia nacional e regional.

Ao tratarmos mais detidamente sobre o projeto nacional de criação e consolidação das Escolas Normais, depreendemos que a própria aspiração por reformas no sistema de instrução pública e pela necessidade de se formar os professores, partiram de uma ambiência política, econômica e social que propiciou esse debate. Nesse sentido, os ideais de ordenamento, progresso e civilização foram enfatizados nos discursos que justificavam a necessidade de se instituir uma Escola Normal para a formação de professores.

Nesse sentido, depreendemos que a iniciativa da Lei $\mathrm{n}^{\mathbf{0}} 33$, de 30 de setembro de 1839, promulgada pelo então Presidente do Grão-Pará, Bernardo de Souza Franco, não obteve sucesso devido a uma não ambiência política, econômica e social que a viabilizasse, diferentemente da Lei $\mathrm{n}^{\circ}$ 669, de 13 de abril de 1871, sancionada pelo Presidente Joaquim Pires machado Portella, pois a cidade de Belém já havia iniciado, desde os anos de 1850, um grande processo de reformas urbanísticas, cabendo então à promoção de uma reforma do cidadão, que ocorreria por meio da instrução, demandando a formação de professores comprometidos com esse projeto da classe abastada da Província, que havia enriquecido por meio do comércio gomífero.

A própria obra "As Escola Normais no Brasil: do Império à República”, organizada por Araújo, Freitas e Lopes (2008), apresenta-nos uma interessante coletânea de artigos, que acabam por ratificar o que constatamos na Província do Grão-Pará, ou seja, apesar desta obra não abranger a Região Norte no processo de criação e consolidação das Escolas Normais no Brasil, a mesma nos apresenta experiências da gênese e do percurso histórico desse tipo de instituição em várias Províncias do Império, o que nos possibilitou o percebimento das nuanças do processo histórico-educacional das Escolas Normais ao longo do século XIX e início do XX, onde depreendemos que nas distintas experiências, os anseios políticos e sociais por reformas urbanas, com ênfase aos preceitos modernos de 
ordem, civilização e progresso, permearam as concepções políticas e sociais em favor da implementação de medidas relacionadas a melhoria dos respectivos sistemas de instrução pública por meio da promoção da formação de professores, onde a Escola Normal desponta como modelo de instituição que melhor atenderia esses anseios.

Torna-se interessante evidenciarmos ainda que os distintos projetos de criação das Escolas Normais, presentes na mencionada obra, acabam por demonstrar que esta instituição esteve também centrada na perspectiva social de criação de novos hábitos sociais de consumo, de mobilidade social e de, fundamentalmente, constituição de mecanismos que viabilizassem a proliferação, entre os cidadãos, de valores específicos das sociedades urbanas e industriais, o que estava em consonância com os preceitos de modernidade defendidos pelos Governantes das Províncias (Cf. ARAÚJO, FREITAS \& LOPES, 2008).

Por essa forma, a opção pelo modelo normalista, nas Províncias, fora em função da supremacia do modelo social europeu, em especial o parisiense, entre a elite dirigente do Império e das Províncias em destaque, pois a Europa, neste momento, apresentava-se aos dirigentes imperiais e provinciais brasileiros como o que havia de melhor em matéria de modernidade. Todavia, não queremos aqui afirmar que apenas o modelo europeu esteve presente no imaginário dos dirigentes brasileiros, mas que o mesmo acabou por se sobressair entre os demais.

Somos conscientes dos limites de nossa narrativa em dar conta da complexidade do projeto de implementação e consolidação das Escolas Normais no Império do Brasil. No entanto, procuramos inicialmente tentar perceber o movimento de ideias e modelos de instrução que estiveram em voga entre os dirigentes do Império e das Províncias.

No caso específico do Grão-Pará, procuramos concatenar os pressupostos discursivos dos Presidentes da Província às teorizações francesas do final do século XVIII, por meio do recurso teórico e metodológico da polifonia bakhtiniana, possibilitando-nos o percebimento da constituição discursiva dos mesmos, que acabamos por ratificar nossa premissa inicial da influência francesa nas questões educacionais no Grão-Pará.

Percebemos ainda, que por meio dos discursos iluministas e liberais, os Presidentes da Província procuravam evidenciar a necessidade de se formar o povo à luz da moral, da ciência e da razão, como forma de habilitar o cidadão aos serviços que viessem a ser chamados a cumprir, o que demandaria uma eficiente formação para os professores primários do Grão-Pará, onde a Escola Normal fora eleita pela maioria de seus dirigentes como sendo um modelo de instituição que melhor formaria este professor e, por conseguinte, o cidadão paraense. Preceitos estes que estiveram em consonância com os discursos nacionais em favor do modelo normalista de formação de professores.

Na Província do Grão-Pará houve ainda um surto de modernização que propiciou um debate e aspirações por amplas reformas sociais, onde podemos inferir que o elemento humano mereceu certo destaque. Ou seja, por meio da ascensão econômica da Província, que esteve intimamente ligada a crescente economia gomífera, a introdução da embarcação a vapor e a abertura do rio Amazonas à navegação internacional, fora suscitado o interesse da classe enriquecida da Província em civilizar o povo, de forma que a reorganização do sistema de instrução pública e a instalação de uma escola destinada ao preparo específico de professores passou a ser objeto de debates e aspirações de sucessivos Presidentes.

É bem verdade que os rendimentos do sistema de instrução pública do Grão-Pará estavam, no período, bem abaixo do esperado, porém a afirmação de que a causa maior era a falta de preparo, vocação, empenho e dedicação dos professores fora uma forma de mascarar a falta de interesse do Governo da Província em promover um profícuo sistema 
de instrução pública, pois haviam graves problemas que impossibilitavam melhores resultados, como o insuficiente número de escolas, os parcos salários dos professores e a falta de mecanismos para a formação e aprimoramento destes.

Vale ressaltarmos que a necessidade de se formar professores, inúmeras vezes debatido pelos Presidentes do Grão-Pará, esteve centrado na perspectiva de se formar um quadro docente à luz dos pressupostos modernos de ordenamento, civilização e progresso, e que estivessem afinados com os pressupostos ideológicos dos políticos conservadores, porque a influência republicana despontava entre amplos setores da sociedade paraense, principalmente pelo viés estadunidense. Nesse contexto, os professores formados pela Escola Normal do Pará seriam responsáveis em conter essa influência e disseminar entre os cidadãos da Província a ideologia conservadora do Governo.

Para além dessa disseminação e inculcação da ideologia conservadora entre os cidadãos paraenses, os Presidentes da Província pretendiam ainda alinhar a sociedade ao que entendiam enquanto moderno e civilizado, onde elegeram o modelo europeu, em especial o parisiense, como esse viés de ordenamento e conduta dos hábitos e costumes sociais, que passavam a ser normatizados por meio dos códigos de posturas municipais, determinando a postura dos cidadãos civilizados que habitavam uma cidade igualmente civilizada.

Em resumo, os debates e aspirações por uma instituição que formasse e habilitasse os professores da Província, que a partir de 1871, por meio da Lei $\mathrm{n}^{\circ} 669$, de 13 de abril do mesmo ano, configurou-se como Escola Normal do Pará, esteve em meio a essas nuanças políticas, econômicas e sociais que permearam esses debates e discursos em favor de profícuos resultados do sistema de instrução pública da Província, mas que resguardavam interesses da classe dirigente e enriquecida do Grão-Pará em manter a ordem social préestabelecida. Isto é, manter seus status políticos e sociais, bem como uma economia alicerçada no trabalho forçado e mal remunerado de negros, brancos e mestiços pobres e marginalizados.

A instrução, nesse contexto, estaria também em função de se desenvolver uma mão de obra qualificada para o mercado industrial que se queria, haja vista que faltavam profissionais habilitados para as funções que as indústrias recém-instaladas na capital da Província demandavam naquele momento.

Destarte, a Escola Normal do Pará nasce dessa intricada questão de disputas políticas e ideológicas entre conservadores e liberais, de forma que sua organização esteve em função dos objetivos daqueles que estiveram à frente do Governo da Província, ratificando a influência européia entre a elite dirigente daquele período, bem como a supremacia do modelo normalista de formação de professores entre essa mesma classe dirigente, que o considerava como eficiente sistema de preparo e habilitação de professores que já vinha sendo implantado em outras Províncias do Império desde a primeira metade do século XIX, que assim como a experiência do Grão-Pará, estiveram em meio a essas disputas políticas e ideológicas, assim como, sob uma ambiência econômica que as possibilitaram.

Cumpre destacarmos ainda as contradições do discurso e da prática dos Presidentes da Província, uma vez que pautavam seus debates nos pressupostos iluministas de ilustração do povo à luz da moral, da razão e do cientificismo, mas o que verificamos fora a falta de investimentos no sistema de instrução pública da Província que atendessem a necessidade de implantação de escolas no interior do Grão-Pará, assim como de melhores ordenados para os professores e a implantação de mecanismos de formação e aperfeiçoamento destes. Além de manterem um sistema de instrução pública excludente, 
uma vez que em nenhum momento de seus discursos e debates se pensou em uma instrução que estivesse ao alcance dos negros, seja negros livres ou escravizados.

Antes de finalizar, ou melhor, de darmos uma pausa neste trabalho, acredito ser importante destacar alguns temas apenas tangenciados por nós, mas que podem ser bastante elucidativos para a história da constituição e consolidação da Escola Normal do Pará. Isso é, a organização das relações de trabalho assentadas com aqueles que possuíam a missão de formar os professores normalistas, as formas de ingresso na instituição, ou seja, quais os critérios adotados para a admissão dos alunos e alunas? Bem como, qual o currículo prescrito para a formação desses professores? A repercussão social dos primeiros professores formados pela instituição, a própria não observância da instrução dos negros da Província, além de inúmeros outros viés de pesquisa que essas nuanças históricas que a Escola Normal do Pará no possibilita por meio da história social. Mas, tudo isso fica para futuras pesquisas e se configura como possibilidades para outros pesquisadores, haja vista que no momento nos dedicamos aos discursos dos Presidentes da Província do Grão-Pará acerca da necessidade de se instituir na capital da Província uma Escola Normal destinada ao preparo específico de professores primários.

\section{Referências}

ARAGO, François. Oeuvres de Condorcet. Biographie, vol. I, Paris: F. Didot frères, $1847-$ 1849, réimp. F. Frommann Verlag, Stuttgart, 1968.

ARAÚJO, José Carlos Souza. A Gênese da Escola Normal de Uberlândia, MG: o contexto estadual e a independência cultural em 1926. In: ARAÚJO, José Carlos Souza; FREITAS, Ana Maria Gonçalves Bueno de; LOPES, Antônio de Pádua Carvalho (orgs.). As Escolas Normais no Brasil: do Império à República. Campinas, SP: Editora Alínea, 2008.

ARAÚJO, José Carlos Souza; FREITAS, Ana Maria Gonçalves Bueno de; LOPES, Antônio de Pádua Carvalho (orgs.). As Escolas Normais no Brasil: do Império à República. Campinas, SP: Editora Alínea, 2008.

BAKER, Keith Michael. The Old Regime and the French Revolution. Chicago, 1987.

BAKHTIN, Mikhail. Estética da Criação Verbal. SP: Martins Fontes, 2010a.

Freudismo. SP: Perspectiva, 2004.

Marxismo e Filosofia da Linguagem. SP: Hucitec, 2009.

Problemas da poética de Dostoiévski. SP: Forense, 2010b.

Questões de Literatura e de Estética. SP: Hucitec, 2010c.

BERMAN, Marshall. Tudo que é sólido desmancha no ar: a aventura da modernidade. São Paulo: Companhia das Letras, 1988.

BRESCIANI, Maria Stella M. Metrópoles: as faces do mundo urbano (as cidades no século XIX). Revista Brasileira de História. São Paulo: Marco Zero, 1985, pp. 35-68. 
BRITO, Elias Santos de. Educazione e instruzione della scuola normale: celebrações e durezas das professoras e professores da Escola Normal na aurora da República paraense (1890-1908). Belém: Universidade Federal do Pará - Monografia de Graduação, 2005.

CHALHOUB, Sidney. Trabalho, Lar e Botequim: o cotidiano dos trabalhadores no Rio de Janeiro na Belle-Époque. São Paulo: Brasiliense, 1986.

COUTEL, C. À l'école de Condorcet. Contre l'orléanisme des esprits. Paris: ellipses/éditions marketing S.A., 1996.

DIÁRIO DE BELÉM. Belém: Typographia nova de Sant'Anna, 15 de março de 1871.

DIÁRIO DO GRAM-PARÁ. A abertura do Amazonas. Belém: Typographia Commercial; Typographia d'A Estrela do Norte, 7 de setembro de 1867.

DIAS, Edinea Mascarenhas. "A Aldeia modernizada: constituição das políticas urbanas”. In: A ilusão do fausto - Manaus (1890-1920). Manaus: Valer, 1999.

FIGUEIREDO, Aldrin Moura de. Belém dos Imigrantes - história e memória. Museu de Arte de Belém, 2004.

FRANÇA, Maria do Perpétuo Socorro de Souza Avelino de. Raízes históricas do ensino secundário público na Província do Grão Pará: o Liceu Paraense. Dissertação de Mestrado, Faculdade de Educação - UNICAMP - Campinas, 1997.

GRAHAN, Richard. "1850-1870”. In: BETHELL, Leslie (ed.), Brazil: Empire and Rupublic, 1822-1930. Cambridge: Cambridge University Press. 1987.

GRANGER, Gilles-Gaston. La mathématique sociale du marquis de Condorcet. Paris: PUF, 1956, rééd., Paris: Odile Jacob, 1989.

GREGÓRIO, Vitor Marcos. Uma face de Jano: a navegação do rio Amazonas e a formação do Estado brasileiro (1838-1867). 2008. Dissertação (Mestrado em História Social) - Faculdade de Filosofia, Letras e Ciências Humanas, Universidade de São Paulo, São Paulo, 2008.

HARDMAN, Francisco Foot. Trem Fantasma: a modernidade na selva. São Paulo: Companhia das Letras, 1988.

Inventários post-mortem - Município da Capital - 1850, 1852, 1853, 1854, 1855, 1856, 1857, 1858, 1859, 1860, 1861, 1862, 1863, 1864, 1865, 1866, 1867, 1868, 1869 e 1870. Arquivo Público do Pará.

KINTZLER, K. C. Condorcet, l'instruction publique et la naissance du citoyen. Paris: Folio - Essais, Minerve, 1994.

KINTZLER, K. C.; COUTEL, C. Notas. In: CONDORCET. Marquis de. Cinq mémoires sur l'instruction públique. Paris: GF-Flamarion, 1994.

LE GOFF, Jacques. História e Memória. Tradução Bernardo Leitão [et al.]. $5^{\mathrm{a}}$ ed. Campinas, SP: Editora UNICAMP, 2003.

Lei N. 669 de 13.04.1871 - Colleção das Leis da Província do Grão-Pará. Tomo XXIII, 1871.

Lei N. 757 de 19.12.1872 - Colleção das Leis da Província do Grão-Pará. Tomo XXIV, 1872. 
MALHEIROS, R. G. Igreja e Estado: discursos, tensões e acordos políticos (1883 - 1891). Belém: Universidade Federal do Pará - Monografia de Graduação, 2008.

Tensões e negociações entre Igreja e Estado: arrazoamentos e acordos políticos e um período de aceleradas transformações. MNEME - REVISTA DE HUMANIDADES, 11(29), 2011 - JAN / JULHO Publicação do Departamento de História da Universidade Federal do Rio Grande do Norte - Centro de Ensino Superior do Seridó - Campus de Caicó. Semestral ISSN - 1518-3394. Disponível em http://www.periodicos.ufrn.br/ojs/index.php/mneme Acesso em: 25 de julho de 2011.

FORMAÇÃO DE PROFESSORES NA PROVÍNCIA DO GRÃO-PARÁ: os discursos de seus administradores acerca da necessidade de se instaurar uma Escola Normal (1838 - 1871). Dissertação de Mestrado, PPGED, ICED, UFPA. Belém, 2012.

MALHEIROS, R. G. \& ROCHA, Genylton O. R. da. INSTRUÇÃO, CIÊENCIA E CIVILIZAÇÃO: a Província do Grão-Pará e as influências francesa e estadunidense nas questões educacionais (1860 A 1870). Revista HISTEDBR On-line, Campinas, n.48, p. $77-$ 92 Dez.2012 - ISSN: 1676-2584.

MATTOS, Ilmar Rohloff de. O tempo Saquarema. Rio de Janeiro: ACCESS, 1994.

MONARCHA, Carlos. A Escola Normal da Praça - o lado noturno das luzes. São Paulo: Editora da Unicamp, 1999.

MOURÃO, Leila. Memórias da Indústria paraense. Belém: FIEPA, 1989.

O LIBERAL DO PARÁ, O Regulamento da instrucção pública, 5 de maio de 1871.

O LIBERAL DO PARÁ. Belém: Typographia d'O Liberal do Pará, 17 de novembro de 1889.

O LIBERAL DO PARÁ. O Regulamento da Instrucção publica. Belém: Typographia d'O Liberal do Pará, 5 de maio de 1871.

PARÁ, Governo da Província do. Relatório ao Exm. Senr. Dr. Francisco Maria Corrêa de Sá e Benevides, pelo Exm. Senr. Dr. Pedro Vicente de Azevedo, por ocasião de passar-lhe a administração da Província do Pará, no dia 17 de janeiro de 1875. Pará: Typographia do Diario do Gram-Pará, 1875. Disponível em: www.crl.edu/areastudies/LAMP/index.htm Acesso em: 25 de abril de 2012.

Relatório apresentado a Assembleia Legislativa Provincial, na primeira sessão da $19^{a}$ legislatura pelo Presidente da Província do Pará, o Excelentíssimo Senhor Doutor Pedro Vicente de Azevedo, em 15 de fevereiro de 1874b. Pará: Typographia do Diario do Gram-Pará, 1874b. Disponível em: www.crl.edu/areastudies/LAMP/index.htm Acesso em: 25 de abril de 2012.

Relatorio apresentado à Assembléa Legislativa Provincial na segunda sessão da $17^{a}$ Legislatura, pelo Dr. Abel Graça Presidente da Provincia. Pará: Typographia do Diario do Gram-Pará, 1871. Disponível em: www.crl.edu/areastudies/LAMP/index.htm Acesso em: 25 de abril de 2012.

Relatório dos Negócios da Provincia do Para. Pará: Typographia de Frederico Rhossard, 1964.

Relatório dos Negócios da Província do Pará eleabora do pelo Secretário Geral da Província Domingos Soares Ferreira Penna, e apresentado pelo Presidente Couto de 
Magalhães à Assembléia Legislativa Provincial, em 15 de agosto de 1864. Pará: Typographia de Frederico Carlos Rhossard, 1864. Disponível em: www.crl.edu/areastudies/LAMP/index.htm Acesso em: 25 de abril de 2012.

Relatório feito pelo Exm. ${ }^{\circ}$ Senr. Doutor Angelo Custódio Correa, $1 .^{o}$ Vice Presidente desta Província, por occasiã̃ de dar posse da administração da mesma, ao Exm. ${ }^{o}$ Senr. Conselheiro Sebastião do Rego Barros, no dia 16 de novembro de 1853. Pará: Typographia de Santos \& Filhos, 1853. Disponível em: www.crl.edu/areastudies/LAMP/index.htm Acesso em: 25 de abril de 2012.

Relatório lido pelo Exm. ${ }^{\circ}$ Vice-Presidente da Província do Pará, Ambrósio Leitão da Cunha, na abertura da primeira sessão ordinária da Assembléia Legislativa Provincial, no dia 15 de agosto de 1858. Pará: Typographia Commercial, 1858. Disponível em: www.crl.edu/areastudies/LAMP/index.htm Acesso em: 25 de abril de 2012.

PESSANHA, Andréa Santos. Em nome do progresso: uma sociedade criada por figuras ilustres na Corte lutou pela imigração europeia como forma de preparar o Brasil para o trabalho livre e "aprimorar" os nacionais. Revista Nossa História. Ano 2 / n 24, outubro de 2005.

SARGES, Maria de Nazaré. Belém: Riquezas produzindo a Belle-Époque (1870-1912). Belém: Paka-Tatu, 2002.

SAVIANI, D. Formação de professores: aspectos históricos e teóricos do problema no contexto brasileiro. Revista Brasileira de Educação, v. 14, n. 40, jan./abr. 2009.

SILVA, Sidney Reinaldo. Direitos humanos e instrução pública segundo Condorcet. Educação em Revista, Marília, v. 11, n.12, p. 1-18, Jan.-Jun. 2010.

VILLELA, H. de O. S. A primeira escola normal do Brasil. In: NUNES, Clarice (Org.). O Passado sempre presente. São Paulo: Cortez, 1992.

VIOTTI DA COSTA, Emilia. Da monarquia a república: momentos decisivos. São Paulo: Brasiliense, 1994. $6^{\text {a }}$. Ed.

XAVIER, Maria Elizabete S. Prado. Poder político e educação de elite. 3.ed., São Paulo: Cortez: Autores Associados, 1992.

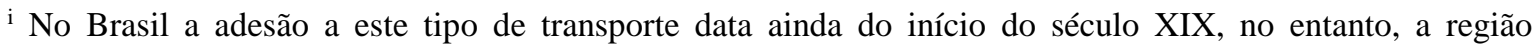
amazônica passa a contar com os navios a vapor somente a partir da segunda metade do mesmo século, apesar de sua introdução na região já ter sido objeto de discussão durante sessões do parlamento brasileiro, ainda na década de 1820, que estaria em consonância com o projeto de desenvolvimento econômico da região, seu povoamento e sua manutenção como território pertencente ao Império do Brasil. Sobre essa questão, Cf.: GREGÓRIO, Vitor Marcos. Uma face de Jano: a navegação do rio Amazonas e a formação do Estado brasileiro (1838-1867). 2008. Dissertação (Mestrado em História Social) - Faculdade de Filosofia, Letras e Ciências Humanas, Universidade de São Paulo, São Paulo, 2008.

ii Por meio dos Relatórios dos Presidentes da Província do Grão-Pará e outras fontes publicadas no período, podemos depreender que houve uma significativa elevação na arrecadação da Província do Pará desde a década de 1840, fato que os Presidentes e autoridades constituídas atribuíram ao crescente comércio da borracha, que anualmente vinha crescendo de forma bem acentuada. Sobre esta questão, Cf.: PARÁ,
} 
Governo da Província do. Relatório dos Negócios da Provincia do Para. Pará: Typographia de Frederico Rhossard, 1964, pp. 59-60.

iii Sobre o remodelamento da cidade de Belém, Cf.: SARGES, Maria de Nazaré. Belém: Riquezas produzindo a Belle-Époque (1870-1912). Belém: Paka-Tatu, 2002.

iv Le Goff (op. cit., p. 185) identifica os termos "modernismo", "modernização" e "modernidade" como uma herança histórica da querela acerca da dualidade antigo/moderno. Segundo o referido historiador, "[...] a Revolução Industrial vai mudar radicalmente os termos da oposição no par antigo/moderno, na segunda metade do século XIX e no século XX". A modernidade, a partir da segunda metade do século XIX, apresenta-se como um conceito intimamente relacionado à estética, a mentalidade e aos costumes de uma dada sociedade. O próprio termo "modernidade" é lançado por Baudelaire (1863, apud LE GOFF, 2003) na década de 1860, que, segundo Le Goff (op. cit., 194), “[...] dá ao significado de moderno uma nuança que o liga aos comportamentos, costumes e decoração. 'Cada época', diz, 'tem o seu porte, o seu olhar, o seu gesto"".

v Sobre a influência do modelo social e urbanístico europeu, em especial o parisiense, no Brasil temos uma vasta obra nacional e internacional que discute essa premissa. Cf.: CHALHOUB, Sidney. Trabalho, Lar e Botequim: o cotidiano dos trabalhadores no Rio de Janeiro na Belle-Époque. São Paulo: Brasiliense, 1986; BERMAN, Marshall. Tudo que é sólido desmancha no ar: a aventura da modernidade. São Paulo: Companhia das Letras, 1988; BRESCIANI, Maria Stella M. Metrópoles: as faces do mundo urbano (as cidades no século XIX). Revista Brasileira de História. São Paulo: Marco Zero, 1985, pp. 35-68; SARGES, Maria de Nazaré. Belém: Riquezas produzindo a Belle-Époque (1870-1912). Belém: Paka-Tatu, 2002; MOURÃO, Leila. Memórias da Indústria paraense. Belém: FIEPA, 1989; HARDMAN, Francisco Foot. Trem Fantasma: a modernidade na selva. São Paulo: Companhia das Letras, 1988; MATTOS, Ilmar Rohloff de. O tempo Saquarema. Rio de Janeiro: ACCESS, 1994; DIAS, Edinea Mascarenhas. "A Aldeia modernizada: constituição das políticas urbanas”. In: A ilusão do fausto - Manaus (1890-1920). Manaus: Valer, 1999; GRAHAN, Richard. "1850-1870”. p. 143. In: BETHELL, Leslie (ed.), Brazil: Empire and Rupublic,1822-1930. Cambridge: Cambridge University Press. 1987; PESSANHA, Andréa Santos. Em nome do progresso: uma sociedade criada por figuras ilustres na Corte lutou pela imigração europeia como forma de preparar o Brasil para o trabalho livre e "aprimorar" os nacionais. Revista Nossa História. Ano 2 / n 24, outubro de 2005; VIOTTI DA COSTA, Emilia. Da monarquia a república: momentos decisivos. São Paulo: Brasiliense, 1994. 6a . Ed.; FIGUEIREDO, Aldrin Moura de. Belém dos Imigrantes - história e memória. Museu de Arte de Belém, 2004.

vi Segundo Saviani (2009, p. 143), “[...] a questão da formação de professores exigiu uma resposta institucional apenas no século XIX, quando, após a Revolução Francesa, foi colocado o problema da instrução popular". Por essa forma, optamos por revisitar as proposições de Jean Antoine Nicolas Caritat, Marquês de Condorcet, que em seu Rapport de 1792, apresenta um projeto de organização da instrução nacional francesa, que, segundo autores como Kintzler (1994), Coutel (1996), Arago (1968), Baker (1987), Granger (1989), Silva (2010), dentre outros, apesar de não ter sido concretizado na forma da lei, configurouse como a base dos sistemas de instrução pública modernos, implementados ao longo do século XIX em diversos países, de diferentes continentes. Sobre esta questão Cf.: MALHEIROS, Rogério G. FORMAÇÃO DE PROFESSORES NA PROVÍNCIA DO GRÃO-PARÁ: os discursos de seus administradores acerca da necessidade de se instaurar uma Escola Normal (1838 - 1871). Dissertação de Mestrado, PPGED, ICED, UFPA. Belém, 2012.

vii Com forte apoio da maioria dos Deputados, principalmente os representantes das Províncias do Pará e do Amazonas, no ano de 1867, por meio do Decreto de $\mathrm{n}^{\circ} 3.920$, de 31 de julho, fora regulamentado a forma pela qual a navegação das embarcações pertencentes a outras nações deveria ser realizada no rio amazonas e seus afluentes, que a partir de então passaram a receber embarcações de diferentes nacionalidades, o que fora recebido com grande entusiasmo pelas classes dirigentes das Províncias do norte, haja vista que acreditavam ser uma medida essencial para o contínuo progresso econômico que a região vinha alcançando desde os anos de 1850. No entanto, a medida só fora oficializada, solenemente, no dia 7 de setembro de 1867 , data em que o Brasil comemorava quarenta e cinco anos de sua independência política de Portugal, e, além da simbologia da data, a cerimônia foi realizada no exato ponto de encontro do rio Amazonas com o Oceano Atlântico, fato igualmente emblemático e simbólico (Cf.: GREGÁRIO, 2008; MALHEIROS \& ROCHA, 2012). 
viii Sobre a influência do modelo estadunidense de ensino, Cf.: MALHEIROS, Rogério. ROCHA, Genylton. INSTRUÇÃO, CIÊNCIA E CIVILIZAÇÃO: a Província do Grão-Pará e as influências francesa $e$ estadunidense nas questões educacionais (1860 A 1870). Revista HISTEDBR On-line, Campinas, n.48, p. 77-92 Dez.2012 - ISSN: 1676-2584.

ix O Liberal do Pará. Belém, 17 de novembro de 1889, p. 1.

${ }^{x}$ Pelo Padroado, o Governo Imperial poderia intervir em assuntos eclesiásticos, podia apresentar candidatos a ocuparem cargos na Igreja como o de Bispo, tinha o direito de aceitar recursos contra as decisões dos Bispos, de cobrar o dízimo dos fiéis católicos e a obrigação de pagar um salário aos Bispos e párocos, além de viabilizar a proteção das Ordens religiosas. O Padroado dava também poderes ao Governo de intervir e estabelecer sansões contra os religiosos que não aceitassem suas determinações. O exemplo mais comum é a "questão religiosa" ocorrida na segunda metade do século XIX, onde os bispos do Pará, Dom Macedo Costa, e de Olinda, Dom Vital, foram presos pelo Governo Imperial por não terem obedecido às ordens do Imperador. Os dois religiosos, assim como Dom Romualdo de Seixas, eram adeptos dos ideais de romanização, desejavam maior autonomia para a Igreja e que se estreitassem suas relações com Roma (Cf. MALHEIROS, R. G. Igreja e Estado: discursos, tensões e acordos políticos (1883 - 1891). Belém: Universidade Federal do Pará - Monografia de Graduação, 2008; . Tensões e negociações entre Igreja e Estado: arrazoamentos e acordos políticos e um período de aceleradas transformações. MNEME REVISTA DE HUMANIDADES, 11(29), 2011 - JAN / JULHO Publicação do Departamento de História da Universidade Federal do Rio Grande do Norte - Centro de Ensino Superior do Seridó - Campus de Caicó. Semestral ISSN - 1518-3394. Disponível em http://www.periodicos.ufrn.br/ojs/index.php/mneme

xi A Escola Normal do Pará é reaberta pelo Presidente Pedro Vicente de Azevedo, por meio do Regulamento 9, de junho de 1874, que reabriu a Escola Normal com diretoria desmembrada do Liceu Paraense (Cf. PARÁ, 1875, p. 21).

Recebido: $\quad$ mar/15 $\quad$ Aprovado: jun/15 